\title{
A Modified Algorithm for Estimating the Radial Cell Size \\ in the Vaganov-Shashkin Simulation Model
}

\author{
Margarita I. Popkova*, Ivan I. Tychkov, \\ Elena A. Babushkina and Vladimir V. Shishov \\ Siberian Federal University \\ 79 Svobodny, Krasnoyarsk, 660041, Russia
}

Received 14.09.2015, received in revised form 23.10.2015, accepted 03.12.2015

\begin{abstract}
To describe the mechanism of tree-ring formation in woody plants influencing by the leading environmental factors is one of the most urgent problems of modern dendroecology. Changing of the tree-ring growth rate at selected intervals in the growing season is determined by the complex influence of climatic factors (e.g. temperature and soil moisture). Using the modified algorithm of the simulation model of growth Vaganov-Shashkin - VS-oscilloscope seasonal growth of cells in tree ring is simulated in the work. New mathematical approach is developed to estimate a cambial activity and seasonal cell production of conifer species. The approach is tested on tree-ring sample of Pinus sylvestris for Khakassian region over 1969-2008. The obtained approach allows to separate a treering growth signal on two components caused by climatic and non-climatic factors.
\end{abstract}

Keywords: tree ring, process-based model, growth rate, cell size.

DOI: $10.17516 / 1997-1389-2015-8-4-495-513$.

(C) Siberian Federal University. All rights reserved

* Corresponding author E-mail address: popkova.marg@gmail.com 


\title{
Модифицированный алгоритм оценки
}

\section{радиальных размеров клеток \\ в имитационной модели Ваганова-Шашкина}

\author{
М.И. Попкова, И.И. Тычков, \\ Е.А. Бабушкина, В.В. Шишов \\ Сибирский федеральныий университет \\ Россия, 660041, Красноярск, пр. Свободный, 79
}

Понимание механизма формирования и роста годичных колец древесньх растений под влиянием ведущуих факторов внешней среды является одной из самых актуальных проблем современной дендроэкологии. Ускорение или замедление скорости роста дерева в отдельнье интерваль сезона определяется совместным влиянием таких климатических факторов, как температура и влажность почвы. С использованием модифицированного алгоритма имитационной модели роста древесных растений Ваганова-Шашкина - VS-осциллографа в работе моделируется сезонный рост клеток в годичном кольце. Предложен новый математический подход к оценке камбиальной активности хвойных и сезонной клеточной продукции, который был протестирован на образце сосны обыкновенной (Pinus sylvestris L.), отобранном в Хакасии, за период с 1969 по 2008 гг. Благодаря данному подходу удалось разделить влияние климатических и неклиматических внешних факторов на формирование клеток в годичном кольие древесных растений.

Ключевые слова: годичные кольца, имитационная модель, скорость роста, размер клетки.

\section{Введение}

В мировой научной литературе представлен достаточно обширный материал по исследованию изменения строения годичных колец хвойных под внешним воздействием различных факторов (Ваганов и др., 1972, 1985; Ваганов, Терсков, 1977; Polge, Keller, 1969; Schweingruber, 1988, 1996; Ваганов, Шашкин, 2000; Vaganov et al., 2006; Anchukaitis et al., 2006; Evans et al., 2006; Touchan et al., 2012). Так как древесные растения не изменяют своего пространственного положения, то число факторов, влияющих на рост и структуру годичных колец, ограничено. При этом на сезонный рост дерева и формирование годичных колец существенное влияние оказывают такие физические факторы, как температура и влажность. Их реконструкция на основе динамики роста и структуры годичных колец позволяет оценить изменчивость среды обитания и восстановить изменения погодных и климатических условий в прошлом.

Клеточная структура годичного кольца является экологической характеристикой роста дерева (Ваганов, 2008). На рис. 1 представлен фрагмент среза формирующегося годичного кольца сосны на конец июня. Ocoбенностью клеточной структуры годичного кольца хвойных признано существование слоев ранней и поздней древесины. В начале сезона вегетации формируются трахеиды большего радиального размера с тонкими 


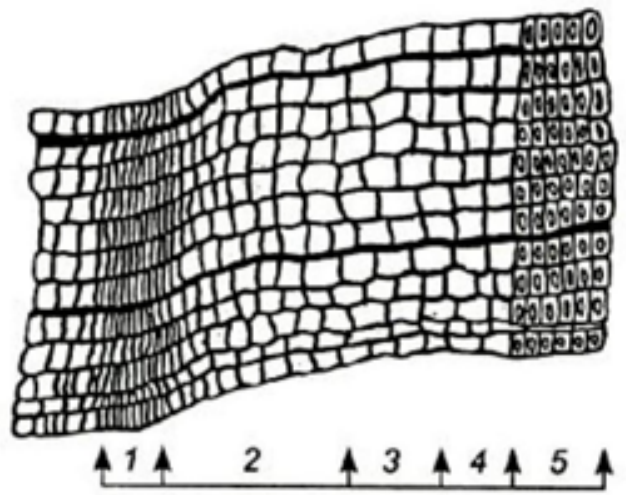

Рис. 1. Формирующееся годичное кольцо: 1 - камбиальная зона; 2 - зона растяжения; 3 - зона утолщения вторичной клеточной стенки; 4, 5 - зрелые трахеиды текущего и предыдущего годов соответственно

стенками - ранняя древесина. Ближе к концу сезона формируются трахеиды меньшего радиального размера с более толстыми стенками - поздняя древесина.

В работе рассматривается пример имитационного моделирования прироста древесных растений с выявлением различных закономерностей в приросте, связанных с изменениями ведущих климатических факторов (температуры и осадков), при помощи нового алгоритма визуальной параметризации - VS-осциллографа, а также известной имитационной модели роста древесных колец Ваганова-Шашкина (VS-модели).

\section{Краткое описание}

\section{имитационной модели}

\section{Ваганова-Шашкина}

Модель формирования годичных колец древесных растений Ваганова-Шашкина (далее VS-модель) описывает влияние климатических условий на клеточную структуру годичных колец (Ваганов, Шашкин, 2000; Vaganov et al., 2006).

В модели рост годичного кольца рассматривается как увеличение численности клеток в одном клеточном ряду в результате делений клеток камбиальной зоны. Клетки растут и делятся, если их размер достигает величины $d_{j}$. Следовательно, скорость роста годичного кольца определяется числом способных к делению клеток и их скоростью роста. Скорость роста клеток зависит от расположения клетки в камбиальной зоне относительно инициали (позиция клетки j), от фазы клеточного цикла и от совокупного действия внешних по отношению к камбию факторов, определяющих и регулирующих рост дерева. Последнее описано в модели через функцию Gr или интегральную скорость роста (Touchan et al., 2012).

Предполагается, что скорость роста дерева зависит от трех основных факторов внешней среды: солнечной радиации, определяющей интенсивность фотосинтеза, температуры воздуха и влагообеспечения. Значение скорости роста $G_{r}$ является функцией трех переменных: текущих значений температуры, содержания влаги в почве и солнечной радиации на каждый день:

$$
G_{r}(t)=G_{I}(t) * \min \left(G_{T m}(t), G_{W}(t)\right),
$$

где $G_{I}(t), G_{T m}(t), G_{w}(t)$ - скорости роста, зависящие от падающей радиации I, температуры Т и влажности почвы W (Тычков и др., 2012). 


\section{Модификация алгоритма}

расчета клеточной продукции

\section{и размеров клетки}

В модели радиального сезонного роста дерева предполагается, что конечный радиальный размер трахеид полностью детерминируется на уровне камбиальных клеток, а изменение относительной скорости роста определяется факторами внешней среды и не зависит от энергии роста дерева (Ваганов и др., 2008).

Кратко опишем этапы построения модели (Ваганов и др., 1985). N(T) - количество трахеид в сформировавшемся годичном кольце, где $\mathrm{T}$ - продолжительность сезона роста. Согласно введенным обозначениям расчет относительной скорости роста числа клеток $v(j, t)$ осуществляется по следующей формуле:

$$
v(j, t)=\frac{1}{N(T)\left(t_{j}-t_{j-1}\right)} .
$$

Для начала определим момент образования новой клетки $t_{j}$ :

$$
t_{j}=\frac{\beta}{N(T)} \sum_{k=1}^{j} \frac{1}{\hat{d}_{k}}=\frac{\mathrm{T} \sum_{k=1}^{j} \frac{1}{\bar{d}_{k}}}{\sum_{k=1}^{N(T)} \frac{1}{\hat{d}_{k}}},
$$

где коэффициент $\beta$ вычисляется на основе экспериментальных данных прошлых лет.

Новая ј-я клетка, появляющаяся в радиальном ряду в момент времени $t_{i}$ в результате деления материнской клетки, вступает в фазу радиального растяжения спустя некоторое время $\tau$ (данное запаздывание принято считать равным 10 суткам) (Ваганов и др., 1985). Размер клетки $d_{j}$ в момент времени $\mathrm{t}$ можно задать уравнением

$$
d_{j}(t)=\alpha\left[k \hat{d}_{j}-d_{j}(t)\right], t \geq t_{j}+\tau,
$$

условии $d_{j}\left(t_{j}+\tau\right)=d_{0}$ решение этого уравнения для $t \geq t_{j}+\tau$ будет

$$
d_{j}(t)=k \hat{d}_{j}-\left(k \hat{d}_{j}-d_{0}\right) \exp \left[-\alpha\left(t-t_{j}-\tau\right)\right]
$$

Формула для размера $j$-й клетки в произвольный момент времени $t$ :

$$
\left\{\begin{array}{c}
d_{j}(t)=d_{0} \text { при } t_{j} \leq t \leq t_{j}+\tau \\
d_{j}(t)=k \hat{d}_{j}-\left(k \hat{d}_{j}-d_{0}\right) \exp \left[-\alpha\left(t-t_{j}-\tau\right)\right] \\
\text { nрu } t_{j}+\tau \leq t \leq t_{j}+\tau+\Delta_{j} \\
d_{j}(t)=\hat{d}_{j} \text { npu } t_{j}+\tau+\Delta_{j} \leq t
\end{array},\right.
$$

в которой за $\Delta_{j}$ обозначим длительность фазы растяжения ј-й клетки. Стоит учесть, что при изменении в расчетах параметров $k$ и $a$ в некоторых случаях можно добиться наибольшего совпадения с экспериментальными данными.

Отметим, что реализация данного блока в фортрановской версии 5.0 модели ВагановаШашкина существенно отличается. Вычисления размеров клеток в данной версии модели основаны на скорости роста $G_{r}(t)$, а также на числе клеток $N$ и продолжительности сезона роста, которые определяются по расчетам из камбиальной модели. Расчет размера $j$-й клетки производится по формуле

$$
d_{j}(t)=d_{\text {min }}+K\left(d_{\text {mean }}-d_{\text {min }}\right) /\left(t_{j}-t_{j-1}\right),
$$

где $d_{\text {mean }}$ и $d_{\text {min }}-$ средний и минимальный размеры трахеид; $K$ - нормирующий множитель.

Скорость роста клетки $v(j, t)$ определяется функцией $v_{0}(j)$, характеризующей зависимость роста от позиции $j$ и от определенной ранее функции роста $G_{r}(t)$ :

$v(j, t)=v_{0}(j) \gamma_{1} G_{r}(t)$, где $v_{0}(j)=\alpha+\beta \gamma_{2} j$.

Здесь $\alpha$ и $\beta$ - численные коэффициенты. Для изменения размера камбиальной зоны 
и продуктивности камбия в фортрановской версии модели также введены два коэффициента $-y_{1}$ и $y_{2}$.

Если функция $v(j, t) \geq v_{\min }(j)$, то клетка сохраняет способность к делению и остается в камбиальной зоне. В описываемой версии модели

$$
\left.v_{\min }(j)=\mathrm{c}_{1} \exp \left(\left(\mathrm{c}_{2}+j \gamma_{2}\right) 0,4\right)-5\right)
$$

где $c_{1}$ и $c_{2}-$ численные коэффициенты, определяющие функцию $v_{\min }(j)$.

Коэффициенты, определяющие функцию $v_{0}(j)$, являются независимыми параметрами, которые необходимо оценить какимлибо способом. Это существенно затрудняет работу с данной версией модели. Поэтому в случае модели радиального сезонного роста был предложен альтернативный алгоритм поиска требуемых параметров.

Итак, каждая клетка камбиальной зоны в радиальном ряде характеризуется величинами: позицией ј в радиальном ряде относительно инициали, радиальным размером - $d(j, t)$ и фазой клеточного цикла, в которой она находится в момент t. Скорость роста $v(j, t)$ клетки определяется двумя уравнениями:

$$
v(j, t)=v_{0}(j) * \tilde{G}(t),
$$

где $v_{0}(j)=y=\alpha+\beta * j+\varepsilon, \tilde{G}(t)-$ средняя интегральная скорость роста клетки с линейными коэффициентами $\alpha$ и $\beta$. Тогда:

$$
\frac{v(j, t)}{\tilde{G}(t)}=v_{0}(j)=y=\alpha+\beta j+\varepsilon
$$

Введем следующее обозначение:

$$
\hat{y}=\alpha+\beta j
$$

Совершенно очевидно, что данную задачу можно свести к нахождению этих параме- тров методом наименьших квадратов. Введем следующий функционал:

$$
F=\sum(y-\hat{y})^{2}
$$

Необходимо найти минимум данного функционала по параметрам $\alpha$ и $\beta$ :

$$
\min _{\alpha, \beta} F=\min _{\alpha, \beta} \sum(y-\hat{y})^{2}=\min _{\alpha, \beta} \sum \varepsilon^{2},
$$

на основании решения системы линейных уравнений:

$$
\left\{\begin{array}{l}
\frac{\partial F}{\partial \alpha}=0 \\
\frac{\partial F}{\partial \beta}=0
\end{array}\right.
$$

Таким образом, авторами работы предложен формальный способ оценки значений $\alpha$ и $\beta$, которые доставляют минимум функционала $F$.

\section{Объекты исследования}

Для исследования были выбраны пять деревьев сосны обыкновенной (Pinus sylvestris L.) (pin1, pin4, pin7, pin17, pin18), произрастающих в Республике Хакасия. Для данных деревьев были проведены клеточные измерения: диаметр трахеиды и толщины клеточной стенки по стандартной методике (Vaganov et al., 2006). Период прямых климатических наблюдений на близлежащей метеостанции Шира составил 37 лет, с 1972 по 2008 г. На рис. 2 проиллюстрированы все пять древесно-кольцевые хронологии для данного периода наблюдений.

\section{Параметризация модели}

На первом этапе была сделана проверка взаимной коррелированности индивидуальных рядов прироста отдельных деревьев. Результаты проверки представлены в табл. 1. 

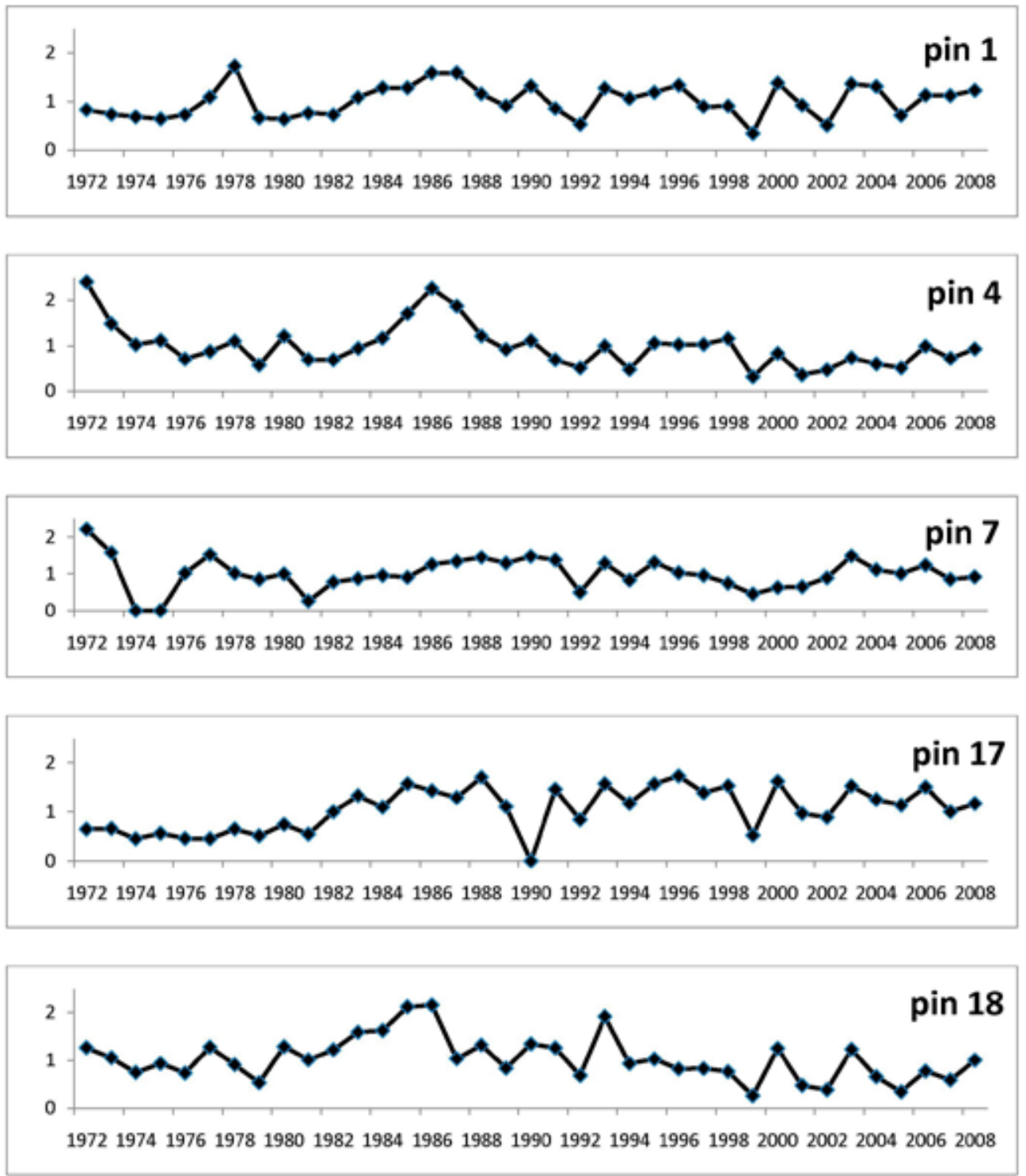

Рис. 2. Хронологии по ширине годичных колец (мм) отдельных деревьев сосны обыкновенной

Таблица 1. Взаимная коррелированность индивидуальных индексных рядов прироста для отдельных деревьев

\begin{tabular}{|c|c|c|c|c|c|}
\hline & pin 1 & pin4 & $\operatorname{pin} 7$ & pin17 & $\operatorname{pin} 18$ \\
\hline pin1 & 1 & 0,4097 & 0,3795 & 0,4597 & 0,5174 \\
\hline pin4 & 0,4097 & 1 & 0,4807 & 0,1298 & 0,6201 \\
\hline $\operatorname{pin} 7$ & 0,3795 & 0,4807 & 1 & 0,1854 & 0,3391 \\
\hline pin17 & 0,4597 & 0,1298 & 0,1854 & 1 & 0,3054 \\
\hline pin18 & 0,5174 & 0,6201 & 0,3391 & 0,3054 & 1 \\
\hline
\end{tabular}

Примечание: жирным шрифтом выделены максимальные значения корреляции. 
Каждой ячейке соответствует значение коэффициента корреляции между выбранными хронологиями. Было рассчитано критическое значение $R_{\text {крит }}=0,32$. Все корреляции в таблице больше заданного критического уровня можно считать значимыми и неслучайными. По результатам проведенного анализа можно сделать вывод о том, что ряды прироста деревьев pin1, pin4 и pin18 обладают наилучшей взаимной коррелированностью. В целом стоит отметить достаточно слабую корреляцию по всем деревьям. Межсериальный коэффиент корреляции Rbar составляет 0,38.

Следующий этап - параметризация модели роста отдельных деревьев. При помощи VS-осциллографа (Тычков и др., 2012; Тычков и др., 2015; Shishov et al., 2015) были подобраны оптимальные параметры имитационный модели, обеспечивающие максимальную синхронность в динамике исходной древесно-кольцевой хронологии и кривой моделируемого прироста. В данном случае под оптимальными параметрами роста древесных растений понимаются параметры, обеспечивающие высокозначимую положительную корреляцию между исходными данными и модельными результатами. Результаты представлены графически и объединены в два блока. В первом блоке (рис. 3) параметры подбирались для достижения максимально возможного значения корреляции. В некоторых случаях даже значимая корреляция между исходной и моделируемой хронологией не гарантировала сохранения дисперсии моделируемой хронологии относительно исходной. Поэтому во втором блоке (рис. 4) параметры подбирались уже с сохранением дисперсии для достижения наилучшего совпадения исходной и модельной хронологии.

Для оптимальной работы модели в конкретных климатических условиях необходимо оценить следующие параметры: 25 параме- тров, отвечающих за интегральную скорость роста древесных колец, и 17 параметров - для определения камбиальной активности (Ваганов, Шашкин, 2000). При этом некоторые из этих параметров являются наиболее информативными, т.е. изменение их значений приводило к значительным изменениям в моделируемой кривой прироста древесного растения. В табл. 2 и 3 перечислены и описаны такие параметры для случаев наибольшего показателя корреляции и наилучшего совпадения дисперсии соответственно.

Анализ данных таблиц показывает, что между значениями одних и тех же параметров (например, см. коэффициенты $\mathrm{C} 1$ и $\mathrm{C} 2$ ), используемых в модели, существуют значимые различия. Это означает, что отдельные деревья, анализируемые в данной работе, росли в различных локальных условиях. Это, в частности, подтверждается анализом парных коэффициентов корреляции, полученных для индивидуальных дендрохронологических индексных рядов отдельных деревьев (см. табл. 1). Так, отмечается низкая средняя коррелированность между отдельными деревьями $(\operatorname{Rbar}=0,38)$. Это означает, что общий сигнал, зафиксированный в годичных кольцах деревьев, является достаточно слабым. В дендрохронологии принято считать, что такой сигнал имеет климатическую природу (Vaganov et al., 2006). Последнее подтверждается и результатами имитационного моделирования прироста отдельных деревьев. Так, для деревьев pin1, pin4, pin7 и pin17 климатическая составляющая объясняет до $16 \%$ общей изменчивости в приросте деревьев. Тогда как для дерева pin18 эта изменчивость составляет около 40 \%. При этом для деревьев со слабой климатической составляющей (до $16 \%$ объясненной изменчивости) модель, описывающая общий климатический сигнал в годичных кольцах, не работает на периоде 

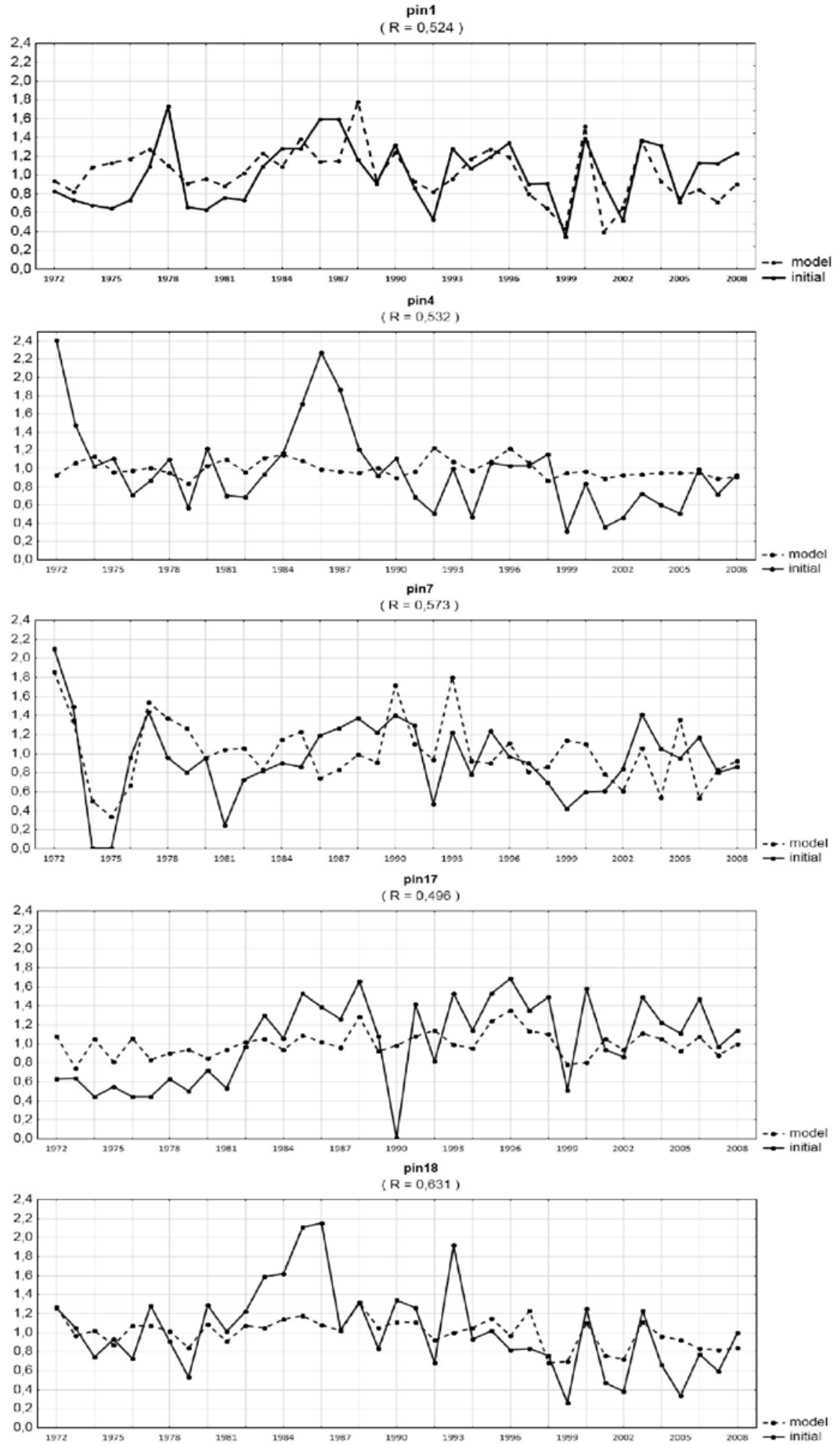

Рис. 3. Динамика моделируемых ростовых кривых и исходные древесно-кольцевые хронологии для пяти деревьев с максимальными значениями коэффициента корреляции между анализируемыми временными рядами (период с 1972 по 2008 г.) 

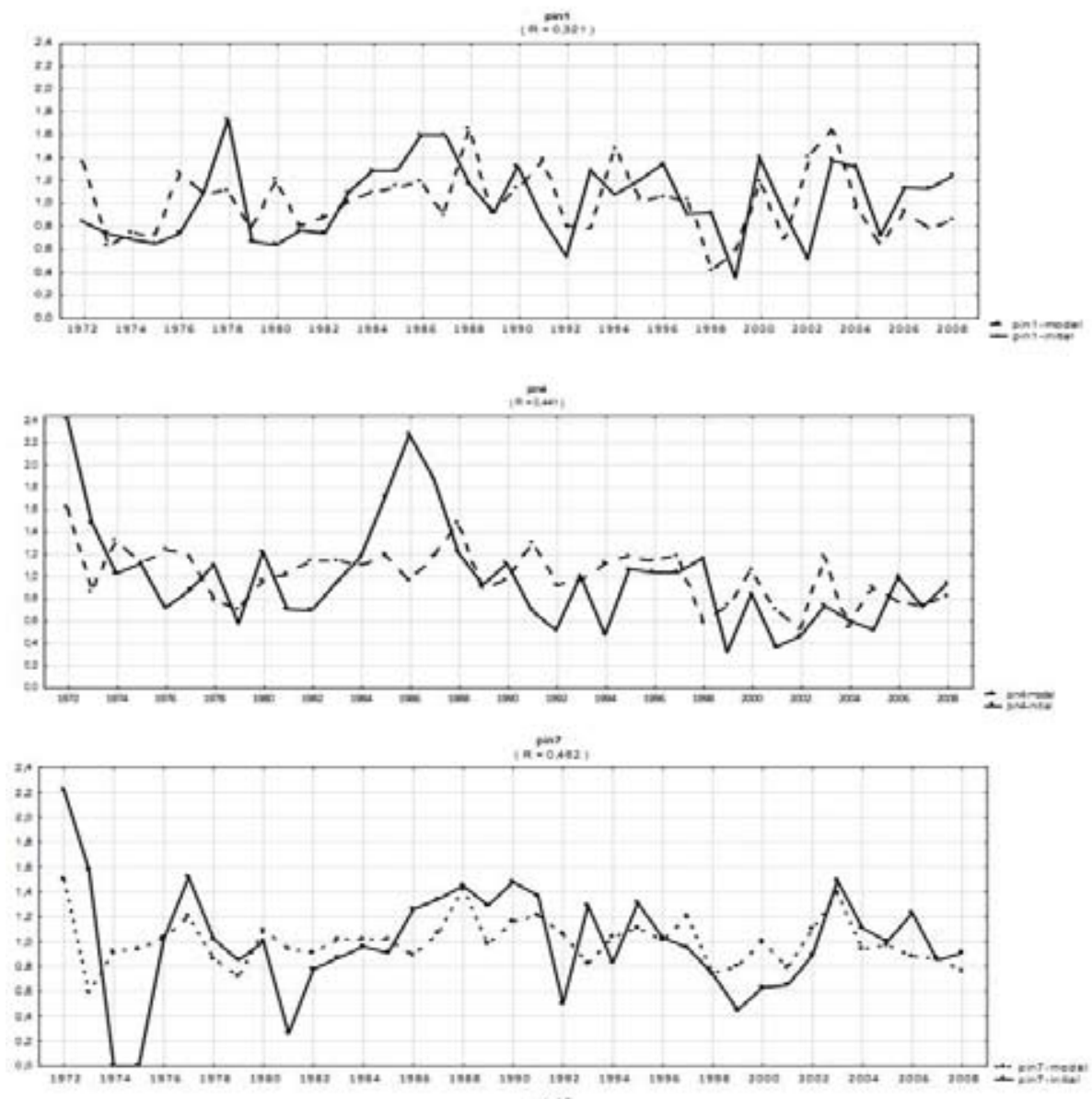

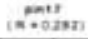

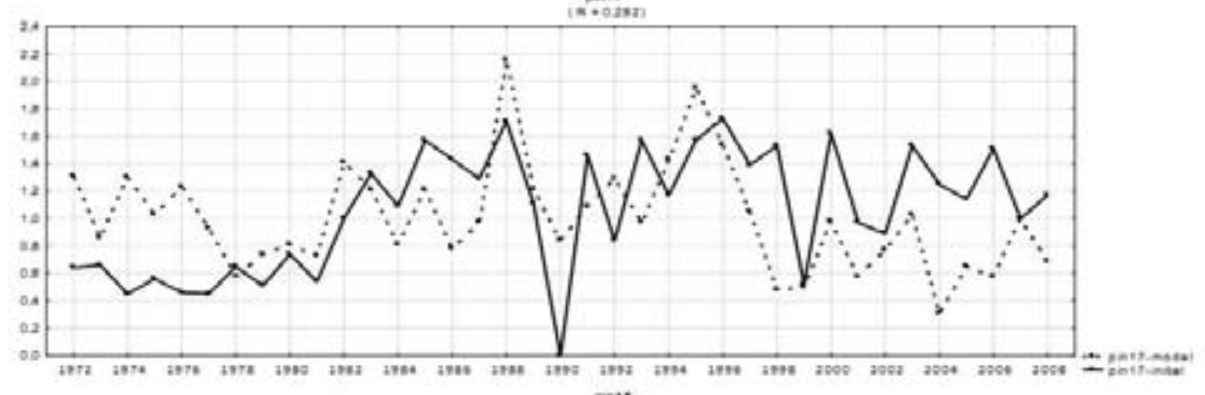
$(\operatorname{mon} 2)$

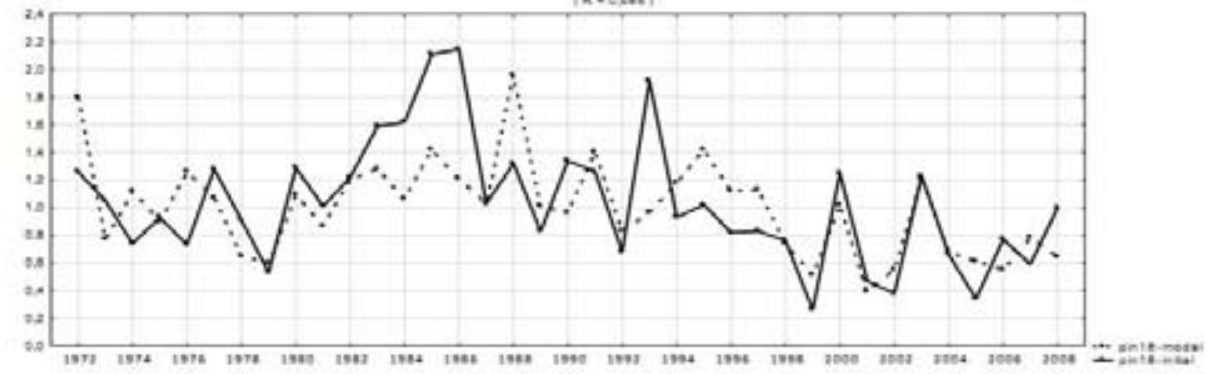

Рис. 4. Динамика моделируемых ростовых кривых и исходные древесно-кольцевые хронологии для пяти деревьев с наилучшим совпадением дисперсии между анализируемыми временными рядами (период с 1972 по 2008 г.) 
Таблица 2. Величины значимых параметров имитационной модели, обеспечивающие максимально возможную положительную корреляцию между исходными данными и модельными результатами

\begin{tabular}{|c|c|c|c|c|c|c|}
\hline \multirow{2}{*}{ Параметр } & \multirow{2}{*}{ Расшифровка } & \multicolumn{5}{|c|}{ Образец } \\
\hline & & pin1 & $\operatorname{pin} 4$ & $\operatorname{pin} 7$ & $\operatorname{pin} 17$ & $\operatorname{pin} 18$ \\
\hline Tmin & Минимальная температура для начала роста $\left({ }^{\circ} \mathrm{C}\right)$ & 3 & 1 & 1 & 3 & 2 \\
\hline Topt1 & $\begin{array}{l}\text { Нижняя граница температуры, при которой интегральная } \\
\text { скорость роста достигает максимума }\left({ }^{\circ} \mathrm{C}\right)\end{array}$ & 4 & 2 & 2 & 4 & 3 \\
\hline Topt2 & $\begin{array}{l}\text { Верхняя граница температуры, при которой интегральная } \\
\text { скорость роста достигает максимума }\left({ }^{\circ} \mathrm{C}\right)\end{array}$ & 25 & 19 & 20 & 13 & 17 \\
\hline $\operatorname{Tmax}$ & $\begin{array}{l}\text { Максимальная температура, при которой возможен рост } \\
\left({ }^{\circ} \mathrm{C}\right)\end{array}$ & 30 & 31 & 35 & 25 & 29 \\
\hline Wmin & Минимальная относительная влажность почвы & 0.05 & 0.02 & 0.07 & 0.03 & 0.01 \\
\hline Wopt1 & $\begin{array}{l}\text { Нижняя граница относительной влажности почвы, } \\
\text { при которой интегральная скорость роста достигает } \\
\text { максимума }\end{array}$ & 0.34 & 0.23 & 0.33 & 0.33 & 0.75 \\
\hline Wopt2 & $\begin{array}{l}\text { Верхняя граница относительной влажности почвы, } \\
\text { при которой интегральная скорость роста достигает } \\
\text { максимума }\end{array}$ & 0.38 & 0.28 & 0.38 & 0.45 & 0.78 \\
\hline Wmax & Максимальная относительная влажность почвы & 0.45 & 0.35 & 0.60 & 0.70 & 0.85 \\
\hline W0 & Начальная относительная влажность почвы & 0.09 & 0.09 & 0.09 & 0.09 & 0.09 \\
\hline Ww & $\begin{array}{l}\text { Минимальная относительная влажность почвы, при } \\
\text { которой начинается завядание }\end{array}$ & 0.04 & 0.04 & 0.02 & 0.08 & 0.02 \\
\hline Tbeg & Суммарная температура для начала сезона роста $\left({ }^{\circ} \mathrm{C}\right)$ & 100 & 100 & 100 & 100 & 100 \\
\hline tbeg & $\begin{array}{l}\text { Количество дней, необходимое для наступления } \\
\text { суммарной температуры (сут) }\end{array}$ & 10 & 10 & 10 & 10 & 10 \\
\hline $1 \mathrm{r}$ & Глубина залегания корней (мм) & 500 & 500 & 500 & 500 & 500 \\
\hline$P \max$ & $\begin{array}{l}\text { Максимальное суточное количество осадков для } \\
\text { достижения насыщения грунта (мм/день) }\end{array}$ & 40 & 40 & 40 & 40 & 40 \\
\hline $\mathrm{C} 1$ & $\begin{array}{l}\text { Количество осадков, проникших в почву } \\
\text { (не остановленных кроной) (отн. ед.) }\end{array}$ & 0.61 & 0.52 & 0.50 & 0.52 & 0.77 \\
\hline $\mathrm{C} 2$ & $\begin{array}{l}\text { Первый коэффициент для вычисления транспирации } \\
\text { (мм/день) }\end{array}$ & 1.75 & 3.10 & 1.70 & 0.90 & 0.10 \\
\hline $\mathrm{C} 3$ & $\begin{array}{l}\text { Второй коэффициент для вычисления транспирации } \\
\text { (мм/день) }\end{array}$ & 0.50 & 0.24 & 0.61 & 0.05 & 0.17 \\
\hline$\gamma$ & Коэффициент дренажа воды из почвы (отн. ед.) & 0.00 & 0.00 & 0.00 & 0.00 & 0.00 \\
\hline$T c$ & Временной шаг камбиальной модели (день) & 1.00 & 1.00 & 1.00 & 1.00 & 1.00 \\
\hline Ver & $\begin{array}{l}\text { Минимальная скорость роста камбиальной клетки } \\
\text { (мкм/день) }\end{array}$ & 0.05 & 0.08 & 0.02 & 0.08 & 0.10 \\
\hline Do & Начальные размеры клетки (мкм) & 4.00 & 4.00 & 4.00 & 4.00 & 4.00 \\
\hline Dcr & $\begin{array}{l}\text { Размер клетки на момент начала митотического ицикла } \\
\text { (мкм) }\end{array}$ & 8.00 & 8.00 & 8.00 & 8.00 & 8.00 \\
\hline$V m$ & $\begin{array}{l}\text { Скорость роста в течении митотического цикла } \\
\text { (мкм/день) }\end{array}$ & 1.00 & 1.00 & 1.00 & 1.00 & 1.00 \\
\hline$D m$ & $\begin{array}{l}\text { Размер камбиальной клетки, при котором начинается } \\
\text { митоз (мкм) }\end{array}$ & 10.00 & 10.00 & 10.00 & 10.00 & 10.00 \\
\hline $\mathrm{Tm}$ & Температура оттаивания почвы & 50 & 30 & 20 & 50 & 30 \\
\hline Sm1 & Первый коэффициент оттаивания почвы $\left(\right.$ мм $\left./{ }^{\circ} \mathrm{C}\right)$ & 10 & 10 & 9 & 10 & 8 \\
\hline $\operatorname{Sm} 2$ & Второй коэффициент оттаивания почвы (ед./день) & 0.0200 & 0.0095 & 0.0070 & 0.0005 & 0.0005 \\
\hline
\end{tabular}

Примечание: курсивом выделены параметры, которые были заданы изначально и не изменяются пользователем. 
Таблица 3. Величины значимых параметров имитационной модели, подобранные для достижения наилучшего совпадения дисперсии между исходными данными и модельными результатами

\begin{tabular}{|c|c|c|c|c|c|c|}
\hline \multirow{2}{*}{ Параметр } & \multirow{2}{*}{ Расшифровка } & \multicolumn{5}{|c|}{ Образец } \\
\hline & & pin1 & pin4 & $\operatorname{pin} 7$ & pin17 & pin18 \\
\hline Tmin & Минимальная температура для начала роста $\left({ }^{\circ} \mathrm{C}\right)$ & 1 & 1 & 4 & 1 & 1 \\
\hline Topt1 & $\begin{array}{l}\text { Нижняя граница температуры, при которой интегральная } \\
\text { скорость роста достигает максимума }\left({ }^{\circ} \mathrm{C}\right)\end{array}$ & 25 & 7 & 13 & 8 & 19 \\
\hline Topt2 & $\begin{array}{l}\text { Верхняя граница температуры, при которой интегральная } \\
\text { скорость роста достигает максимума }\left({ }^{\circ} \mathrm{C}\right)\end{array}$ & 31 & 16 & 20 & 12 & 29 \\
\hline Tmax & $\begin{array}{l}\text { Максимальная температура, при которой возможен рост } \\
\left({ }^{\circ} \mathrm{C}\right)\end{array}$ & 33 & 34 & 27 & 29 & 33 \\
\hline Wmin & Минимальная относительная влажность почвы & 0.02 & 0.06 & 0.05 & 0.04 & 0.05 \\
\hline Wopt1 & $\begin{array}{l}\text { Нижняя граница относительной влажности почвы, } \\
\text { при которой интегральная скорость роста достигает } \\
\text { максимума }\end{array}$ & 0.15 & 0.75 & 0.55 & 0.50 & 0.20 \\
\hline Wopt2 & $\begin{array}{l}\text { Верхняя граница относительной влажности почвы, } \\
\text { при которой интегральная скорость роста достигает } \\
\text { максимума }\end{array}$ & 0.40 & 0.83 & 0.65 & 0.65 & 0.55 \\
\hline Wmax & Максимальная относительная влажность почвы & 0.88 & 0.90 & 0.75 & 0.73 & 0.95 \\
\hline$W 0$ & Начальная относительная влажность почвы & 0.09 & 0.09 & 0.09 & 0.09 & 0.09 \\
\hline $\mathrm{Ww}$ & $\begin{array}{l}\text { Минимальная относительная влажность почвы, при } \\
\text { которой начинается завядание }\end{array}$ & 0.03 & 0.07 & 0.07 & 0.07 & 0.06 \\
\hline Tbeg & Суммарная температура для начала сезона роста $\left({ }^{\circ} \mathrm{C}\right)$ & 100 & 100 & 100 & 100 & 100 \\
\hline tbeg & $\begin{array}{l}\text { Количество дней, необходимое для наступления } \\
\text { суммарной температуры (сут) }\end{array}$ & 10 & 10 & 10 & 10 & 10 \\
\hline 1r & Глубина залегания корней (мм) & 500 & 500 & 550 & 600 & 650 \\
\hline$P \max$ & $\begin{array}{l}\text { Максимальное суточное количество осадков для } \\
\text { достижения насыщения грунта (мм/день) }\end{array}$ & 40 & 40 & 40 & 40 & 40 \\
\hline $\mathrm{C} 1$ & $\begin{array}{l}\text { Количество осадков, проникших в почву } \\
\text { (не остановленных кроной) (отн.ед.) }\end{array}$ & 0.85 & 0.58 & 0.69 & 0.77 & 0.65 \\
\hline $\mathrm{C} 2$ & $\begin{array}{l}\text { Первый коэффициент для вычисления транспирации } \\
\text { (мм/день) }\end{array}$ & 3.85 & 2.35 & 0.15 & 1.95 & 0.40 \\
\hline $\mathrm{C} 3$ & $\begin{array}{l}\text { Второй коэффициент для вычисления транспирации } \\
\text { (мм/день) }\end{array}$ & 0.17 & 0.22 & 0.33 & 0.25 & 0.36 \\
\hline$\gamma$ & Коэффициент дренажа воды из почвы (отн. ед.) & 0.00 & 0.00 & 0.00 & 0.00 & 0.00 \\
\hline$T c$ & Временной шаг камбиальной модели (день) & 1.00 & 1.00 & 1.00 & 1.00 & 1.00 \\
\hline Ver & $\begin{array}{l}\text { Минимальная скорость роста камбиальной клетки } \\
\text { (мкм/сут) }\end{array}$ & 0.09 & 0.08 & 0.04 & 0.09 & 0.07 \\
\hline Do & Начальные размеры клетки (мкм) & 4.00 & 4.00 & 4.00 & 4.00 & 4.00 \\
\hline Dcr & $\begin{array}{l}\text { Размер клетки на момент начала митотического ицикла } \\
\text { (мкм) }\end{array}$ & 8.00 & 8.00 & 8.00 & 8.00 & 8.00 \\
\hline$V m$ & $\begin{array}{l}\text { Скорость роста в течении митотического иикла } \\
\text { (мкм/день) }\end{array}$ & 1.00 & 1.00 & 1.00 & 1.00 & 1.00 \\
\hline$D m$ & $\begin{array}{l}\text { Размер камбиальной клетки, при котором начинается } \\
\text { митоз (мкм) }\end{array}$ & 10.00 & 10.00 & 10.00 & 10.00 & 10.00 \\
\hline $\operatorname{Tm}$ & Температура оттаивания почвы & 20 & 30 & 50 & 20 & 10 \\
\hline Sm1 & Первый коэффициент оттаивания почвы $\left(\right.$ мм $\left./{ }^{\circ} \mathrm{C}\right)$ & 10 & 15 & 10 & 10 & 6 \\
\hline $\mathrm{Sm} 2$ & Второй коэффициент оттаивания почвы (ед/день) & 0.0075 & 0.0015 & 0.0060 & 0.0050 & 0.0045 \\
\hline
\end{tabular}

Примечание: курсивом выделены параметры, которые были заданы изначально и не изменяются пользователем. 
верификации. Таким образом, для всех деревьев за исключением дерева pin18, моделирование можно считать неудовлетворительным (неадекватным). Последнее заключение может объяснять существенную разницу между значениями отдельных параметров, используемых в модели.

По результатам проведенной параметризации было выбрано дерево ріn18 с наилучшим значением коэффициента корреляции, для которого построены графики сезонных интегральных скоростей роста (рис. 5), парциальных скоростей роста по влажности почвы (рис. 6) и по температуре (рис. 7) для каждого года периода в интервале с 1972 по 2008 г.

Результаты параметризации образца pin18 с использованием VS-осциллографа были проверены на программе Growth 5.0, основанной на имитационной модели роста древесных колец Ваганова-Шашкина. Сравнение результатов, полученных в результате параметризации выборочного дерева с использованием VS-осциллографа и программы Growth 5.0, представлены на рис. 8. Обе модельные хронологии были построены с использованием одинакового набора параметров, которые были подобраны на VSосциллографе и продублированы для программы Growth 5.0. Различия в результатах объясняются модификациями алгоритма, реализованного в фортрановском коде, при написании программы VS-осциллографа (Тычков и др., 2015).

\section{Потенциальная возможность моделирования}

\section{радиальных клеточных размеров}

На примере древесного образца pin18 coсны обыкновенной, отобранного в Хакасии, осуществлена VS-параметризация древеснокольцевой хронологии отдельного дерева за период с 1972 по 2008 г. Используя данные, полученные в результате работы модели Ваганова-Шашкина, мы разработали новый подход к оценке камбиальной активности и сезонной продукции клеток, который позволяет разделить климатические и неклиматические факторы в процессе формирования клеток. Результаты представлены на графиках зависимости радиальных размеров клеток и относительных скоростей роста от номера в клеточном ряду (рис. 9, 10). Были проанализированы все сезоны роста с 1969 по 2008 г. для отобранного древесного образца. Статистически незначимые расхождения (проверка проводилась на основании F-критерия, уровень значимости $\mathrm{p}=0.05$ ) между наблюдаемым и смоделированным профилями диаметральных размеров клеток имеются в $74 \%$ случаев (рис. 9). Это означает, что из 40 проанализированных сезонов роста в 30 случаях модифицированный камбиальный блок хорошо моделирует сезонные клеточные профили по радиальному диаметру клеток (суммарное значение радиального размера люмена и клеточной стенки). Следовательно, для данного конкретного примера имитационная модель Ваганова-Шашкина в $74 \%$ случаев хорошо описывает сезонную клеточную продукцию на основании использования значений суточной температуры и осадков. С другой стороны, статистически значимые расхождения между наблюдаемым и смоделированным профилями диаметральных размеров клеток, соответственно, составляют $26 \%$ (рис. 10). Анализ смоделированных клеточных профилей по отношению к наблюдаемым (или измеренным) показывает, что для 10 сезонов роста смоделированные клеточные профили были всегда интегрально выше, чем наблюдаемые. Это означает, что ведущие климатические факторы благоприятствовали росту древесных растений. Но наблюдаемые клеточные 


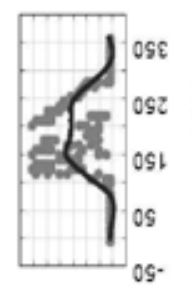

4

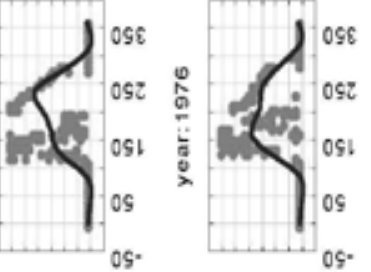

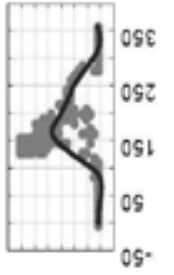

OS
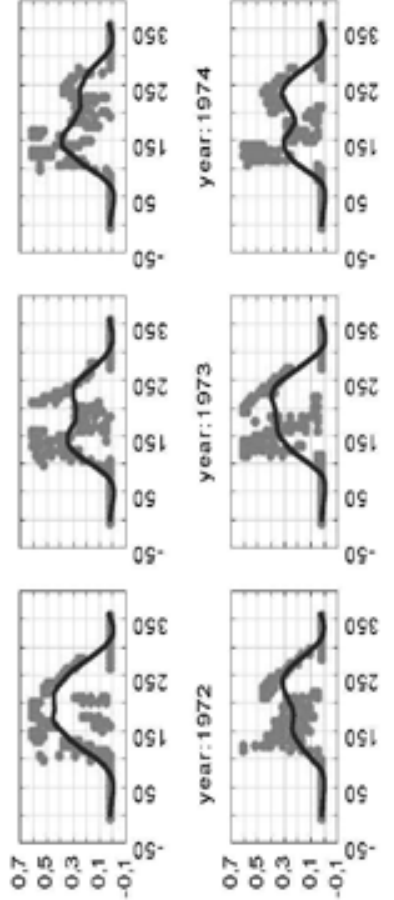
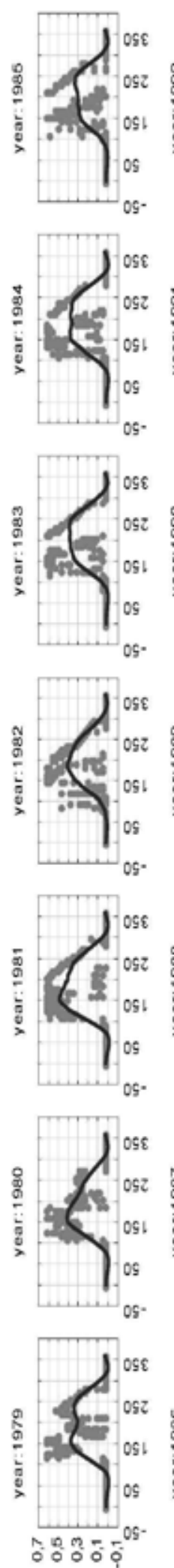
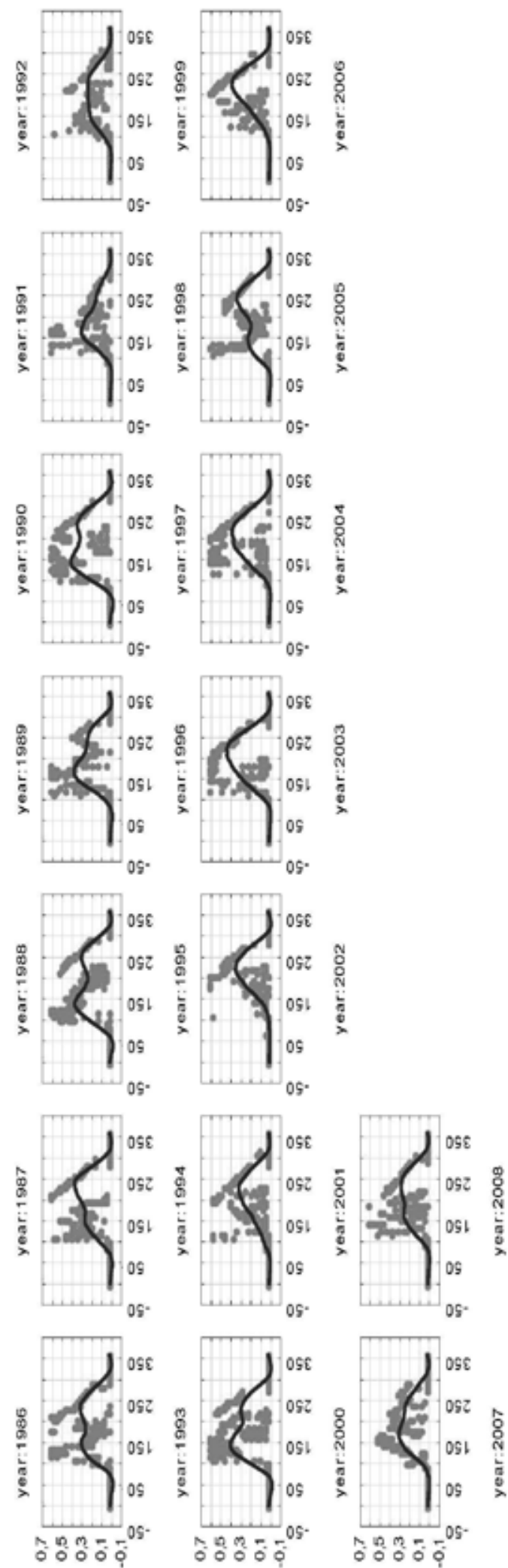

ป

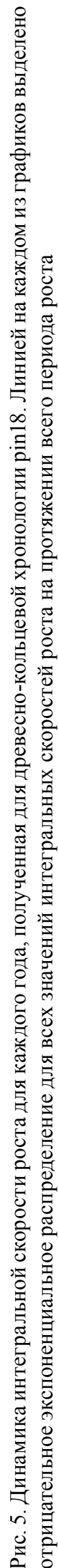




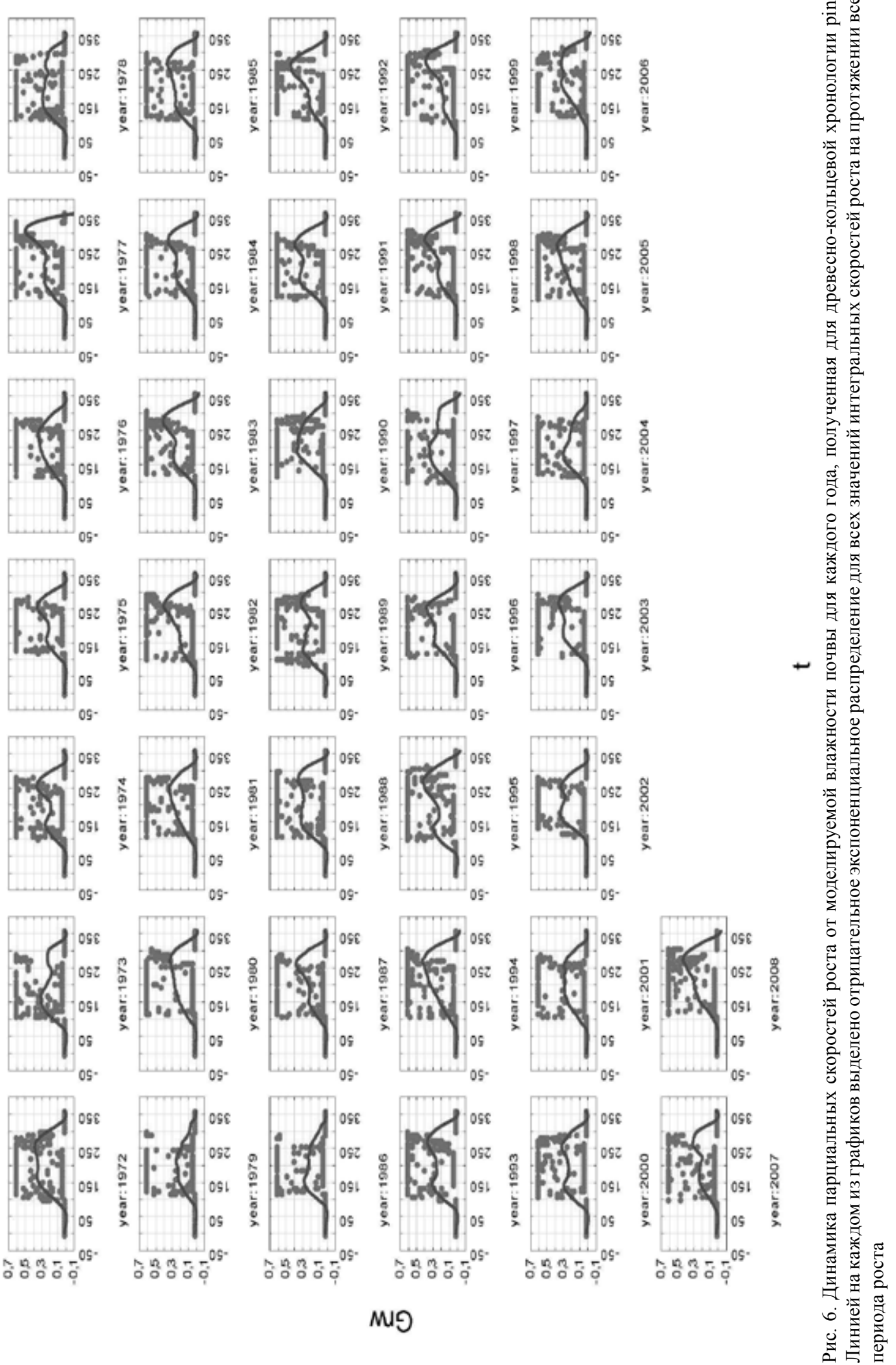



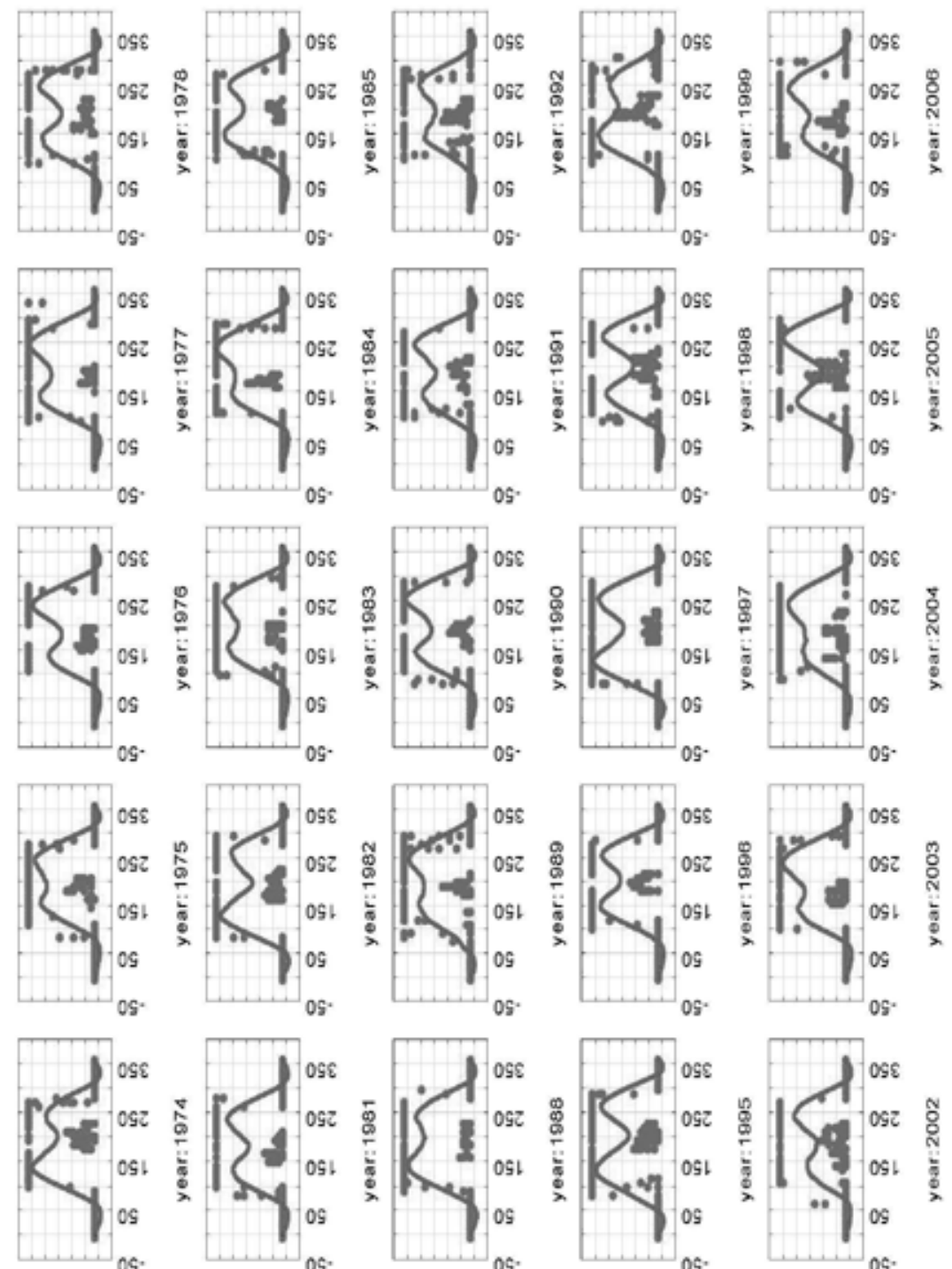

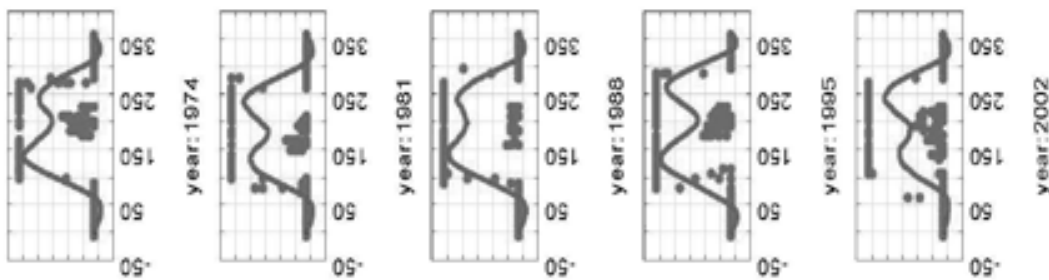
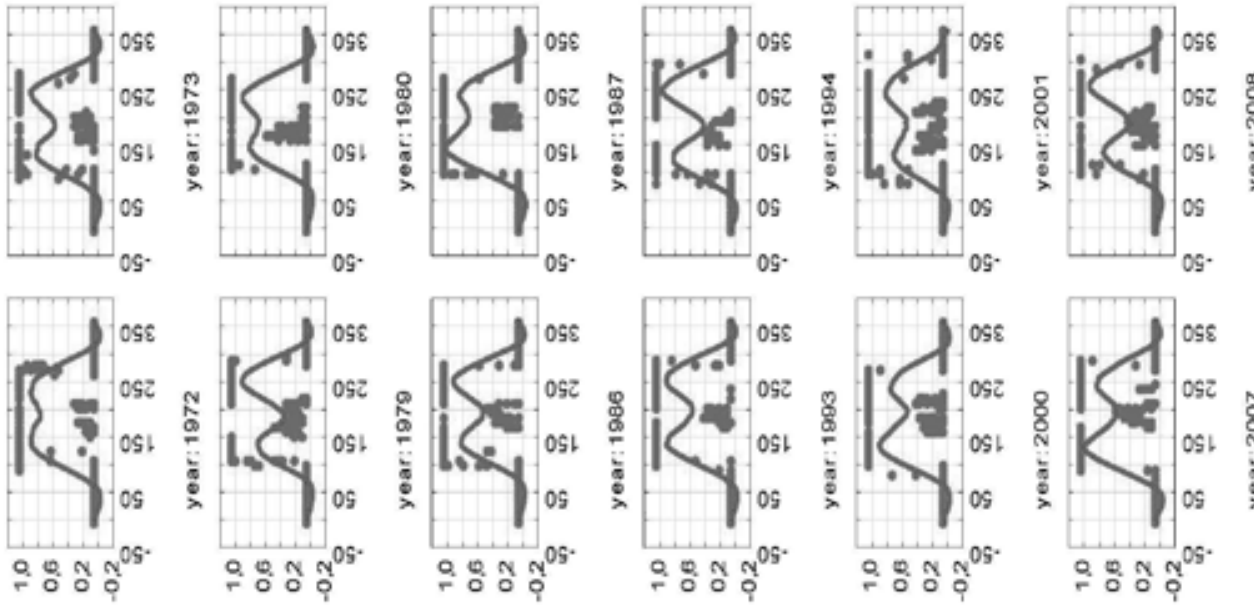


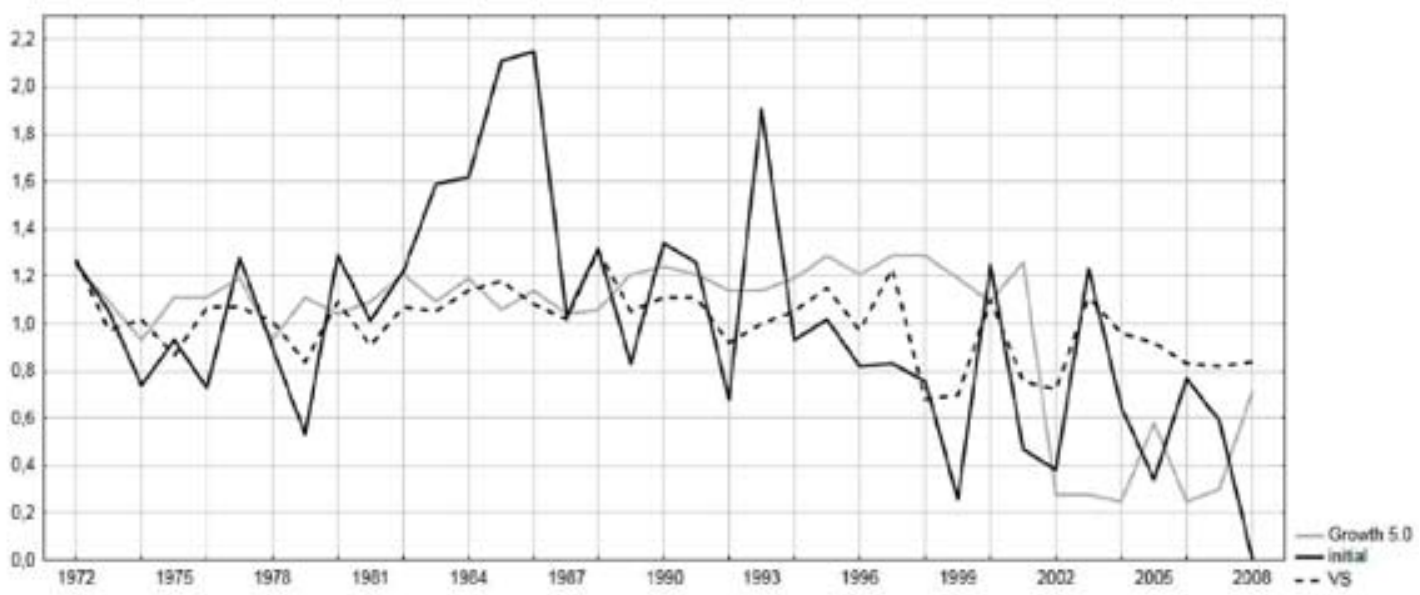

Рис. 8. Сравнение результатов параметризации модели роста дерева рin 18 с использованием программы VS-осциллограф и программы Growth 5.0, реализованной на языке программирования Фортран. Черная сплошная линия - исходная хронология, серая линия - параметризация с использованием программы Growth $5.0(\mathbf{R}=\mathbf{0 . 3 3})$, пунктирная линия - параметризация с использованием VS-осциллографа $(\mathbf{R}=\mathbf{0 . 6 3 1})$
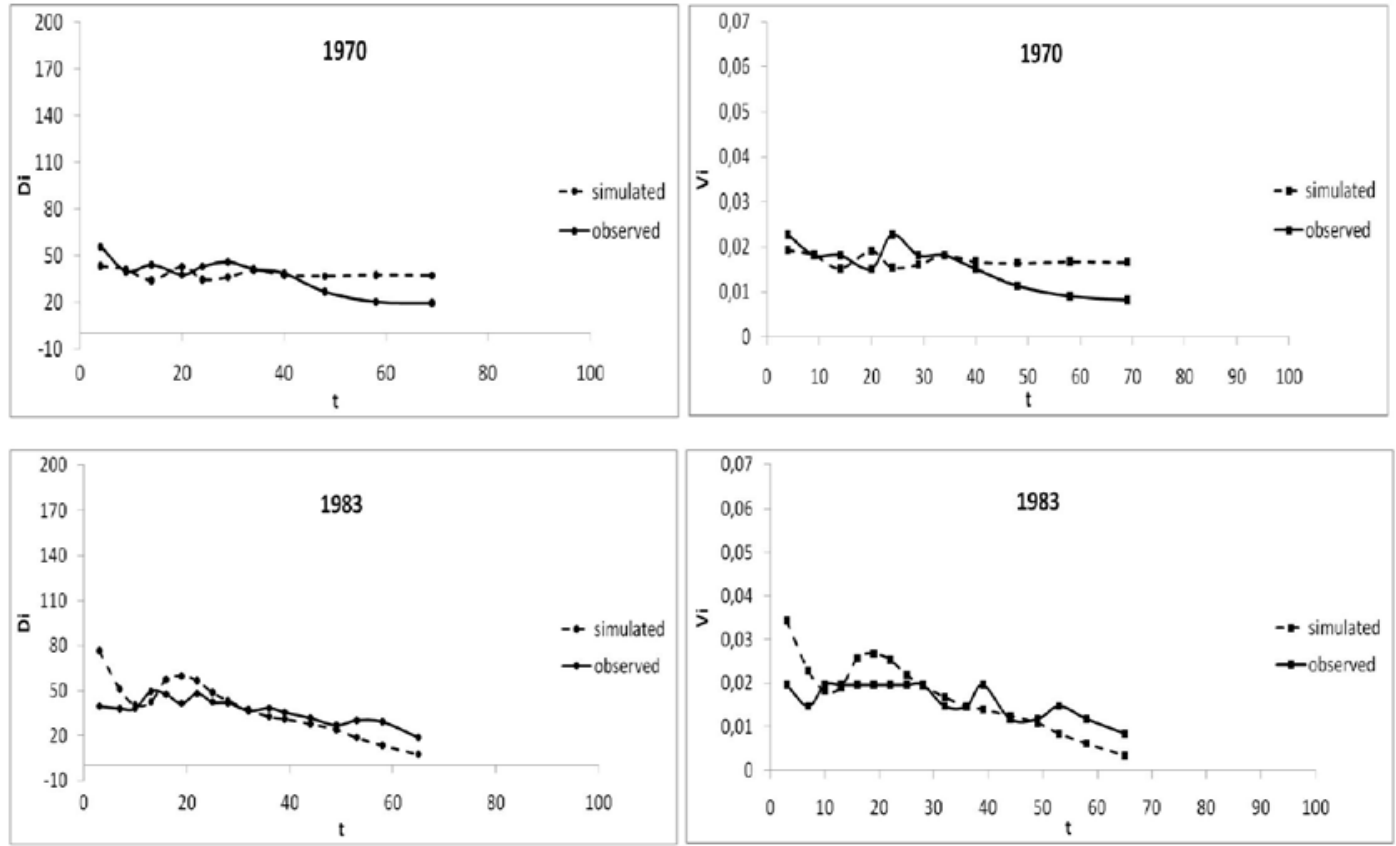

Рис. 9. Графики зависимости радиальных размеров клеток (слева) и относительных скоростей роста (справа) от номера в клеточном ряду для характерных лет. Пример статистически незначимых (p>0.05) расхождений между наблюдаемым (черная сплошная линия) и смоделированным (серая пунктирная линия) профилями диаметральных размеров клеток 

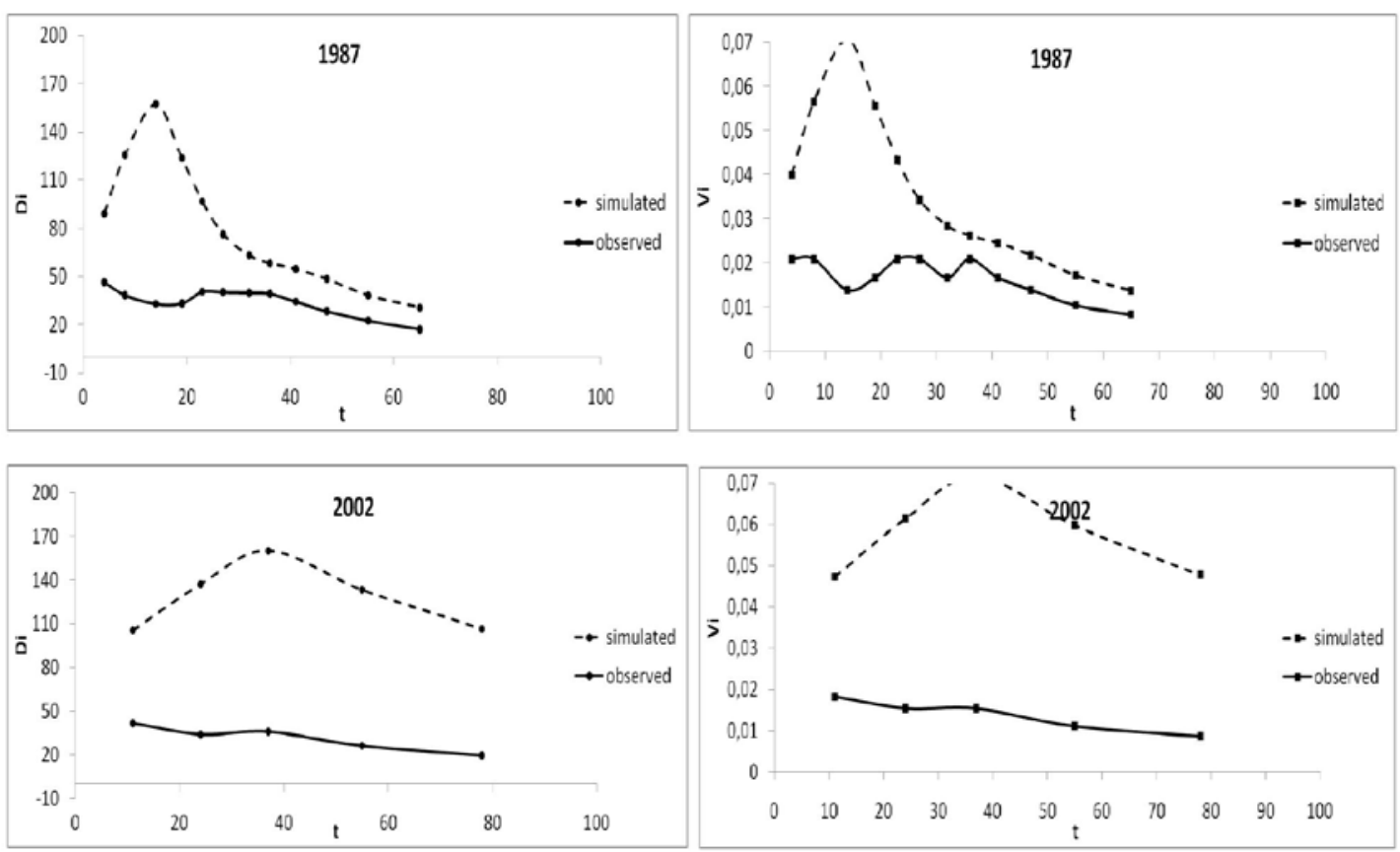

Рис. 10. Графики зависимости радиальных размеров клеток (слева) и относительных скоростей роста (справа) от номера в клеточном ряду для характерных лет. Примеры статистически значимых $(\mathrm{p}<0.05)$ расхождений между наблюдаемым (черная сплошная линия) и смоделированным (серая пунктирная линия) профилями диаметральных размеров клеток в определенные сезоны роста

профили были интегрально существенно ниже, т.е. можно сделать предположение, что на процесс формирования клеток в определенные сезоны роста начинает оказывать влияние дополнительный лимитирующий фактор неклиматической природы, который угнетает рост древесного организма. На данном этапе работы невозможно определить, что это за фактор: пожар, вспышка массового размножения насекомых, ветровал и т.п., так как отсутствуют задокументированные данные для подобного рода событий в пределах анализируемой пробной площади.

\section{Заключение}

В последнее время появилась серия работ, касающаяся моделирования клеточной продукции древесных растений (Cuny et al., $2012,2013,2014)$. При этом авторы используют очень формальный подход к описанию процесса формирования клеток хвойных в течение сезона роста на основе так называемой кинетики развития трахеид. По сути, используются оценки скорости роста клеток с последующей их трансформацией в количество и собственно размеры, что было сделано российскими учеными еще в 1985 г. (Ваганов и др., 1985). Но основной вопрос: «Как оценить скорость роста клеток (скорость формирования трахеид) под действием внешних факторов?» - остается открытым. Описанный выше в этой работе подход на основе имитационного моделирования роста годичных колец древесных растений позволяет вплотную подойти к этой проблеме.

На основании всего вышесказанного можно сделать следующие заключения:

- Разработан новый алгоритмический подход к оценке камбиальной актив- 
ности и формированию радиальных размеров клеток.

- Данный подход протестирован на пяти древесных образцах сосны обыкновенной (Pinus sylvestris), собранных в Хакасии (Южная Сибирь, Россия).

- Этот подход позволяет отделить влияние факторов климатической и некли- матической природы в процессе формирования клеток.

В дальнейшем для тестирования этого алгоритма планируется использовать данные с пробных площадей из других географических регионов, других пород древесных растений и, по возможности, с хорошо документированной историей событий для конкретного местообитания.

\section{Работа была поддержана грантом Российского научного фонда (проект № 14-14- 00219).}

\section{Список литературы}

Ваганов Е.А., Шашкин А.В., Свидерская И.В., Высоцкая Л.Г. (1985) Гистометрический анализ роста древесных растений. Новосибирск, Наука, 104 с. [Vaganov E.A., Shashkin A.V., Sviderskaya I.V., Vysockaya L.G. (1985) Gistometrical tree growth analis. Novosibirsk, Nauka, 104 p. (in Russian)]

Ваганов Е.А., Шиятов С.Г. (1999) Важность дендрохронологических и дендрогидрологических исследований в изучении глобальных и региональных проблем. Сиб. экол. журн., 2: 68-74 [Vaganov E.A., Shiyatov S.G. (1999) The importance of dendrochronological and dendrogidrological researches in the study of global and regional issues. Siberian Journal of Ecology [Sibirskii ekologicheskii zhurnal], 2: 68-74 (in Russian)].

Ваганов Е.А., Круглов В.Б., Васильев В.Г. (2008) Дендрохронология. Красноярск, СФУ, 120 c. [Vaganov E.A., Kruglov V.B., Vasiliev V.G. (2008) Dendrochronology. Krasnoyarsk, SFU, 120 p. (in Russian)]

Тычков И.И., Леонтьев А.С., Шишов В.В. (2012) Новый алгоритм параметризации модели роста годичных колец деревьев: VS-осциллограф и его применение в дендроэкологии. Cистемbl. Meтодbl. Технологии, 4 (16): 45-51 [Tychkov I.I., Leontiev A.S., Shishov V.V. (2012) The new algorithm of a parameterization model of tree rings growth: VS-oscilloscope and its application in dendroecology. System. Methods. Technology [Sistemy. Metody. Tekhnologii], 4 (16): $45-51$ (in Russian)].

Тычков И.И., Коюпченко И.Н., Ильин В.А., Шишов В.В. (2015) Визуальная параметризация имитационной модели Ваганова-Шашкина и её применение в дендроэкологических исследованиях. Журнал СФУ. Биология, 8 (4): 475-491 [Tychkov I.I., Koyupchenko I.N., Ilyin V.A., Shishov V.V. (2015) Visual parameterization of Vaganov-Shashkin simulation model and its application in dendroecological research. J. Sib. Fed. Univ., Biol., 8 (4): 475-491(in Russian)].

Anchukaitis K.J., Evans M.N., Kaplan A., Vaganov E.A., Hughes M.K., Grissino-Mayer H.D., Cane M.A. (2006) Forward modeling of regional scale tree-ring patterns in the southeastern United States and the recent influence of summer drought. Geophys. Res. Lett., 33: L04705. DOI: 10.1029/2005GL025050.

Cuny H.E., Rathgeber C.B.K., Lebourgeois F., Fortin M., Fournier M. (2012) Life strategies in intra-annual dynamics of wood formation: example of three conifer species in a temperate forest in north-east France. Tree Physiology, 32: 612-625. 
Cuny H.E., Rathgeber C.B.K., Senga Kiesse T., Hartmann F.P., Barbeito I., Fournier M. (2013) Generalized additive models reveal the intrinsic complexity of wood formation dynamics. Journal of Experimental Botany, 64: 1983-1994.

Cuny H.E., Rathgeber C.B.K., Frank D., Fonti P., Fournier M. (2014) Kinetics of tracheid development explain conifer tree-ring structure. New Phytologist, 203: 1231-1241.

Evans M.N., Reichert K., Kaplan A., Anchukaitis K.J., Vaganov E.A., Hughes M.K., Cane M.A. (2006) A forward modeling approach to paleoclimatic interpretation of tree-ring data. Journal of Geophysical Research, 111: 980-989.

Shishov V.V., Tychkov I.I., Popkova M.I., Ilyin V.I., Bryukhanova M.V., Kirdyanov A.V. (2015) VS-oscilloscope: A new tool to parameterize tree radial growth based on climateconditions. Dendrochronologia. DOI: 10.1016/j.dendro.2015.10.001.

Sweingruber F.H. (1996) Tree Rings and Environment. Dendroecology. Birmensdorf, Swiss Federal Institute for Forest, Snow and Landscape Research. Berne, Stuttgart, Vienna, Haupt.

Touchan R. (2012) Process based model sheds light on climate sensitivity of Mediterranean treering width. Biogeosciences, 9: 965-972.

Vaganov E.A., Hughes M.K., Shashkin A.V. (2006) Growth Dynamics of Conifer Tree Rings Images of Past and Future Environments. Berlin, Heidelberg, Springer-Verlag, 367 p. 